\title{
Gasification of SRF in a GazEla fixed bed reactor
}

\author{
A. Sobolewski, T. Iluk \& M. Szul \\ Institute for Chemical Processing of Coal, Zabrze, Poland
}

\begin{abstract}
This paper presents the results of solid recovered fuel (SRF) gasification research in a GazEla fixed bed reactor on pilot installation with $60 \mathrm{~kW}_{\text {th }}$ output. Proprietary construction of the gasifier has an innovative character and was developed by the Institute for Chemical Processing of Coal, IChPW (Poland). This paper aims to present the results acquired during preliminary gasification tests of biomass and SRF mixtures. The innovative character of this reactor construction has been presented and set in comparison with other reactor designs used by authors conducting similar research around the world. Detailed process analysis and characterization of observed peculiarities of SRF as an admixture for gasification fuel are done, with attention put towards setting base line limits and conditions for providing stable gasification process parameters. The presented tests are compared with standard process parameters developed for the gasification of biomass (wood chips) in the reactor, as it is the main fuel this reactor has been developed for. The main goal of this research programme is the development of small and medium scale gasification installation for distributed energy systems generating heat and power in combined units (CHP) based on a piston engine. As such, the acquired results are set in comparison with other author's work, mainly in the field of fixed bed SRF gasification for generation of heat and power in piston engine, with determination of influence introduced by different process scales. The next step in this research will be the development of appropriate process parameters to conduct tests of solely SRF gasification in a pilot installation $\left(60 \mathrm{~kW}_{\text {th }}\right)$ and further preparation for tests at demonstrative scale installation $\left(1.5 \mathrm{MW}_{\mathrm{th}}\right)$.
\end{abstract}

Keywords: fixed bed, SRF, gasification. 


\section{Introduction}

Extreme rate of development and industrialization presented by the world of today has provided humanity with better life quality on day to day basis. The price which needs to be paid for those facilitations is immense. Namely still growing energy demand presented by developing and developed countries as well as noncompensated amount of waste generated in the process. These two connected and non-separable phenomena generate threat which needs to be identified and dealt with in the nearest future by countries all over the world.

Power industries seek for a renewable, cheap source of energy which preferably would be highly accessible in the long run, due to danger of imminent depletion of primary energy sources.

Countries look for a mean of waste management and control to stop a flood of waste which is transported to landfills, due to rapidly depleting safe area for waste storage.

These two above mentioned problems inspired research facilities to develop advances energy recovery systems which would enable generation of power from waste. Two technologies providing means of being applicable for this problem are incineration and gasification $[1,2]$.

Incineration is primarily intended for reduction of waste stream volume, which further needs to be landfilled and additionally may be connected with energy recovery processes providing heat and/or power. Unfortunately due to very small efficiencies of energy recovery reached by such systems $(\sim 20 \%$, [3]), severe emission standards which need to be attained and very poor social response for this technology causes a situation where extend of its application is highly limited.

Gasification on the other hand offers inherent ability to attain higher efficiencies of energy recovery as well as provides easier and cheaper means of emission control. Other extremely important aspect of gasification is the range of final products which can be generated. Basic division generates two very much different means of technology development. The more basic and straight forward is generation of process gas for its application in heat and/or heat and power systems [4]. Second is generation of syngaz with appropriate $\mathrm{CO} / \mathrm{H}_{2}$ ratio for production of hydrogen, liquid fuels, ammonia, alcohols or power generation in fuel cells application [5].

Additionally actions has been taken towards standardization of fuels derived from waste materials for provision of easy comparison between different fuel applicability for different processes. Unsorted Municipal Solid Wastes, MSW, may serve as a fuel in its primary form. But such operation often provides many hardship due to poor homogeneity of fuel and large fraction of recyclable material which would be lost in the process. That is why different treatment strategies have been developed for homogenization, recovery of material and provision of highly energetic fuel derived from waste and available for the energy market. Today we find all over the world different types, by this their acronyms, of waste derived fuels. Their production may be according to different standards (national, regional or company standards) but ultimate goal is often the same. As an example refuse derived duel RDF or solid recovered fuel SRF may serve. In North America RDF 
is a more often encountered notion of waste derived fuel, and it is subjected towards standardization. On the other hand in Europe a notion of SRF is the more developed and defined one. SRF is a fuel produced from non-hazardous waste and complying with standards set by European Committee for Standardization in a norm CEN/TC 343. It has been primarily developed for needs of cemetery industry to provide it with mean of reducing the consumption of primary energy sources such as hard and brown coal. On the other hand SRF provides a stream of energy from cheaper, renewable, safe and abundant energy source. This fuel is also attractive for other energy sectors and now a days is utilized in a number of facilities around the world generating heat and power from SRF by means of gasification process [6]. Today a large scale installations of SRF gasification are present in a noticeable number and even more are to come. However the same cannot be told about small and medium scale installation which would serve the same purpose.

Due to this IChPW has undertaken a research activity towards development of SRF gasification installation for combined heat and power production in CHP unit based on piston engine. This research has been enabled by an international research programme coordinated by KIC InnoEnergy.

\section{Results and discussion}

\subsection{Pilot installation}

Located in the IChPW, an installation is a pilot scale gasification installation of $60 \mathrm{~kW}_{\text {th }}$ power. It comprises of four main units i.e.: fuel transportation and storage, reactor, gas cleaning and process gas utilization unit (combustion chamber and power generator.

The installation has been built around a GazEla reactor, which is a proprietary construction developed by IChPW. The reactor is a fixed bed 3 zone gasifier with centrally fitted pipe for process gas evacuation. Construction of the reactor is a cylindrical stainless steel cylinder lined with refractory materials. It has $400 \mathrm{~mm}$ in inner diameter and $900 \mathrm{~mm}$ of technological height. Air or mixtures of air and steam are primarily used as a gasification agent. Reactor takes advantages from both downdraft and updraft fixed bed reactors while removes inherent to them downsides. The 3 zone character of the gasifier is provided by the fact of gasification agent provision into upper reactor zone - above the bed, into the middle reactor zone and below the reactor grate. Such system of gasification agent feeding provides means of reactor control and enables generation of process gas which has a high lower heating value, low tar content and has a high outlet temperature. Figure 1 provides general ideological scheme of the reactor and process zones brought forth by its construction.

Pilot installation has been set to provide research conditions closely resembling small scale installations (up to $1.5 \mathrm{MW}_{\text {th }}$ ) while still enabling ease of adjustment and operation. It enables research of process gas cleaning in two different systems, namely dry and wet one, for its final utilization in CHP unit based on piston engine. 
During primary tests and times of engine start-up process gas is directed into gas combustion chamber which provides safe and reliable means of its utilization without consideration of its cleanliness or chemical energy stream comprised in it.
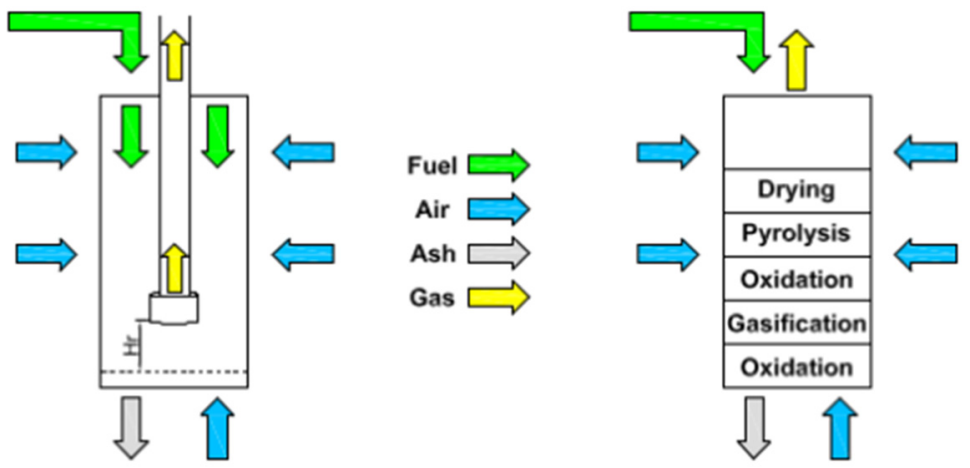

Figure 1: Ideological scheme of GazEla reactor.

\subsection{Tested fuel}

Biomass (wood chips) is a nominal fuel for which GazEla reactor has been designed. It provides base line conditions and stands as a standard in comparison to results acquired by gasification of different types of alternative fuel. During this stage of research attention has been set upon determination of reactor operating conditions and finding an influence of SRF admixture in gasified fuel on the process. Table 1 provides information about ultimate and proximate analysis of both. Samples of SRF has been provided to IChPW in a fluffy form, with moisture content (as received) equal to $24.8 \%$. Due to this and for the sake of proper fuel feeding system operation SRF has been pelletized and then mixed with biomass in $40 \%, 50 \%$ and $60 \% \mathrm{w} / \mathrm{w}$ ratios of SRF in the gasified fuel mixture.

Table 1: Properties of gasified fuel.

\begin{tabular}{|c|c|c|c|c|c|c|c|c|}
\hline & $\begin{array}{c}\text { ash } \\
\text { content, } \\
\mathrm{A}^{\mathrm{a}} \\
{[\%]}\end{array}$ & $\begin{array}{c}\text { volatile } \\
\text { matter } \\
\text { content, } \mathrm{V}^{\mathrm{a}} \\
{[\%]}\end{array}$ & $\begin{array}{c}\mathrm{C}^{\mathrm{a}} \\
{[\%]}\end{array}$ & $\begin{array}{c}\mathrm{H}^{\mathrm{a}} \\
{[\%]}\end{array}$ & $\begin{array}{c}\mathrm{N}^{\mathrm{a}} \\
{[\%]}\end{array}$ & $\begin{array}{c}\mathrm{O}^{\mathrm{a}} \\
{[\%]}\end{array}$ & $\begin{array}{c}\mathrm{S}^{\mathrm{a}} \\
{[\%]}\end{array}$ & $\begin{array}{c}\text { Hower } \\
\text { Heating } \\
\text { Value, } \\
\text { LHV } \\
{[\mathrm{J} / \mathrm{g}]}\end{array}$ \\
\hline SRF & 18.50 & 67.94 & 49.02 & 6.38 & 1,11 & 22.28 & 0.34 & 15369 \\
\hline $\begin{array}{c}\text { wood } \\
\text { chips }\end{array}$ & 0.50 & 78.97 & 48.5 & 5.75 & 0.19 & 40.15 & 0.02 & 15654 \\
\hline
\end{tabular}

a - dry basis (analytic state).

ar - as received (working state). 


\subsection{Results and discussion}

Table 2 presents results of SRF/biomass mixtures and solely biomass preliminary gasification tests in GazEla reactor (air as gasification agent), this table also provides a comparison with results acquired by other authors.

Conducted literature survey provides very few information about air gasification of MSW, RDF or SRF in fixed bed reactors. It may be due to the fact that a number of research actions across the world is concentrated on development of large scale installations and by this the more sound option of fluidized bed reactors is chosen for studies. This of course is linked with the scale of a problem which large cities has to face, i.e. the share amount of generated wastes and power demand. On the other hand though the same problem is also easily noticeable for small municipalities and secluded communities. Jet still there does not exist a technology which would be an answer for their needs. But the technology would not only by a solution for one problem, it would also provide an opportunity for generation of new worksites for local people while bringing more safe and reliable own source of heat and power.

Such application of SRF production technology and its possible utilization brings forward reasoning under development of small and medium scale gasification systems for generation of heat and power in CHP units based on piston engine.

All presented results of SRF gasification tests performed in GazEla reactor were acquired during preliminary test and were not submitted for optimization. This data were needed to draw a bottom line of reactor operating conditions and develop knowledge about what influence does SRF have on the gasification process in GazEla reactor.

Quoted research results from China, Japan and Canada were acquired in bench scale installations with electrically heated fixed bed reactors set for steam gasification of RDF. Stated results correspond to nitrogen free gas and by its nature should be called as syngas. Relative ease of access to data concerning steam gasification of waste derived fuel, either is fixed or fluidized bed reactors present a trend for research frontier aimed at development knowledge oriented at generation of syngas for production of liquid fuels or hydrogen. The only data which is able to be directly applied for comparison is research conducted in Thailand. Reactor there was a fixed bed downdraft system (process was also an air gasification) of similar dimensions to GazEla pilot installation. What is needed to be stated is the fact that in all above mentioned research actions, results of fuel ultimate and proximate analysis showed larger calorific value than SFR used in this study, even though some gasified samples were developed from only slightly pre-processed municipal solid wastes.

Figure 2 presents results of continuous analysis of generated process gas during GazEla reactor run on biomass and on SRF/biomass mixture. It provides a view on process stability and on quality of generated product. Figure on the left presents standard run of GazEla reactor on alder chips, while the one on the right presents exemplary test of $20 \% \mathrm{w} / \mathrm{w} \mathrm{SRF/biomass} \mathrm{mixture} \mathrm{gasification} \mathrm{test.}$ 


\begin{tabular}{|c|c|c|c|c|c|c|c|c|}
\hline Uే & 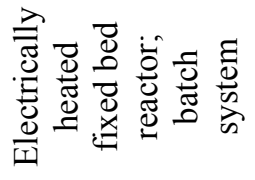 & E. & 竞 & $\simeq$ & in & ป & 이 & 6 \\
\hline 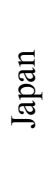 & 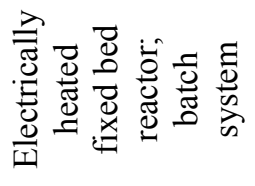 & 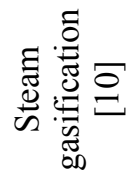 & 崩 & $\stackrel{N}{N}$ & $\stackrel{\infty}{\sim}$ & $\stackrel{0}{0}$ & $\stackrel{\mathcal{F}}{ }$ & $\infty$ \\
\hline . & 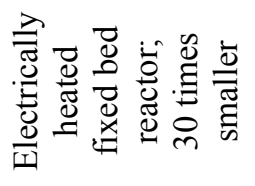 & E & 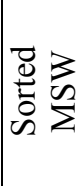 & $\frac{n}{a}$ & $\tilde{\overbrace{}}$ & $\begin{array}{l}\mathcal{f} \\
\stackrel{f}{j}\end{array}$ & $\begin{array}{l}n \\
\stackrel{n}{0} \\
\sim\end{array}$ & $\begin{array}{l}0 \\
0 \\
+\end{array}$ \\
\hline 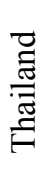 & 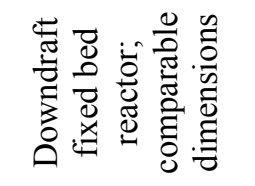 & 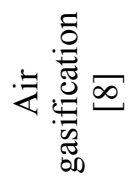 & $\stackrel{1}{2}$ & $\stackrel{g}{\stackrel{g}{+}}$ & $\begin{array}{l}0 \\
\infty \\
\sigma\end{array}$ & $\stackrel{+}{\check{\tau}}$ & ठ̊. & م̊ \\
\hline \multirow{4}{*}{ 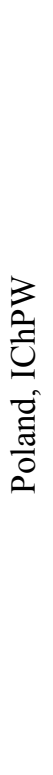 } & \multirow{4}{*}{ 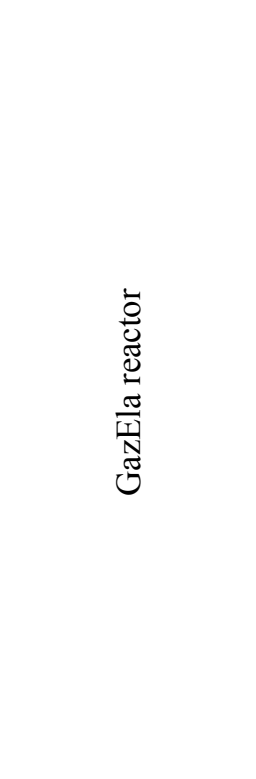 } & \multirow{4}{*}{ 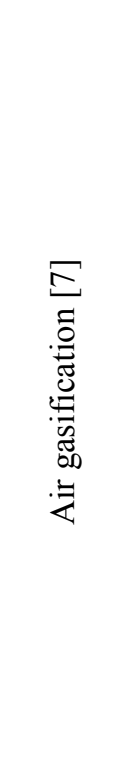 } & $\begin{array}{ll}0 & \\
0 & \\
\vdots & 3 \\
0 & 3 \\
0 & 3 \\
0 & 0 \\
\frac{1}{2} & 0 \\
\frac{n}{\infty} & 0\end{array}$ & $\begin{array}{l}n \\
0 \\
\dot{n}\end{array}$ & $\begin{array}{l}\hat{\gamma} \\
\dot{\gamma}\end{array}$ & ก̂́ & $\stackrel{\infty}{\sim}$ & $\stackrel{\sim}{\sim}$ \\
\hline & & & 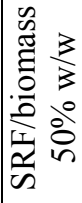 & $\begin{array}{l}\underset{1}{+} \\
\dot{\sigma}\end{array}$ & $\stackrel{\bar{C}}{\check{\nu}}$ & $\stackrel{2}{n}$ & $\begin{array}{l}\vec{\nabla} \\
\dot{v}\end{array}$ & in \\
\hline & & & 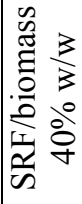 & $\begin{array}{l}\bar{\infty} \\
\dot{+}\end{array}$ & $\underset{N}{N}$ & $\stackrel{\hat{\gamma}}{0}$ & $\begin{array}{l}\infty \\
\infty \\
0\end{array}$ & $\stackrel{n}{\underset{f}{r}}$ \\
\hline & & & $\frac{\bar{\theta}}{\tilde{z}}: \stackrel{n}{\frac{\pi}{0}}$ & $\begin{array}{l}\bar{n} \\
n\end{array}$ & $\frac{\grave{c}}{\mathrm{~N}}$ & $\stackrel{n}{\check{c}}$ & 뭄 & $\begin{array}{l}n \\
n \\
n\end{array}$ \\
\hline 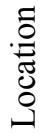 & & 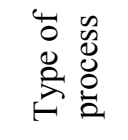 & & $\underset{\Xi}{\Xi}$ & 0 & రీ & $\mathcal{I}$ & $\stackrel{\mathbb{Z}}{\Xi}$ \\
\hline
\end{tabular}



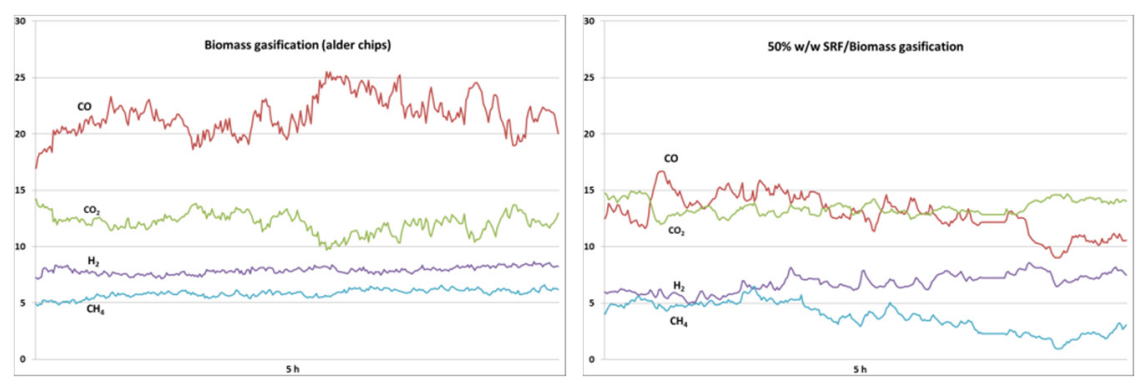

Figure 2: Process gas composition in time; $5 \mathrm{~h}$ period; gasification of alder chips on the left; gasification of $50 \% \mathrm{w} / \mathrm{w} \mathrm{SRF} /$ biomass mixture on the right.

Both presented tests were conducted for minimum $18 \mathrm{~h}$ and a selected $5 \mathrm{~h}$ period has been presented above. As can be seen a much higher stability of generated process gas may be observed for gasification of wood chips. This is due to occurrence of a very stable temperature profile within the reactor. It is noteworthy that both runs were conducted for reactor operating at its full capacity i.e. $60 \mathrm{~kW}$ in fuel. During presented tests reactor had respectively $\eta=73 \%$ cold gas efficiency for biomass gasification and $\eta=62 \%$ cold gas efficiency for $\mathrm{SRF} /$ biomass mixture gasification (table 2 presents averaged values of gas composition and respective LHV).

Tests of SRF and biomass mixtures gasification showed clear differences in reactor operating conditions compared to those observed for gasification of biomass.

First observed difference lied in the way process zones have developed within the reactor. SRF influenced stability of process in a negative manner. Gasified mixtures showed fluctuations in temperature profiles observed within the reactor and this on the other hand caused changes in development of reaction zones. Those fluctuations were clearly visible even for the smallest ratios of SRF in fuel.

Second important aspect influencing process stability is the fact of much lower ash sintering temperatures presented by SRF in comparison to alder chips. Unfortunately it comes together with inherent trend to increase process temperatures at the grate of reactor (maximal attainable temperature on reactor grate for biomass gasification is $1200^{\circ} \mathrm{C}$ for biomass and up to $1450^{\circ} \mathrm{C}$ for gasification of SRF/biomass mixture), what even further increases technological problems with grate blockage. Due to specific construction of the reactor such phenomena has an additional strongly undesirable effect, it indirectly transfers the process gas collecting point. This change, decreases quality of generated process gas due to the fact that collected gas originates from a combustion zone instead of a gasification zone within the reactor. This is predominant after few hours of continuous reactor operation.

Reported technological problems are inherent to registered physicochemical characteristics of SRF. During laboratory test of the fuel recorded ash sintering temperatures under gasification conditions reached as low as $900^{\circ} \mathrm{C}$. Such low 
temperatures come close to a range of optimal SRF gasification temperatures for production of process gas with high calorific value and with low tar content. The problem has been broadly discussed in literature connected with gasification of SRF in fluidised bed reactors. Construction of fixed bed reactors causes them to be less susceptible to this phenomena because ash sintering can be managed by incorporation of very strict temperature control or by development of moving grate system which would enable to continuously remove sintered ash from the surface of reactor grate. IChPW has selected the later as an option for this problem due to several reasons. The most significant one is the fact that for fixed bed reactor to be operated economically and in a sound, controlled manner it needs to be controlled and conducted far in the "autothermal" regime. The heat sink at the grate serves its purpose increasing rate of endothermic gasification reactions. By this it has a great impact on reactor capacity and efficiency. This option also removes problem of feed nonhomogenity and sensitivity towards change of fuel properties.

As for the fact of process control and keeping reaction zones under control during long run of the reactor, a strategy similar to a one developed for other alternative fuels is thought to serve the purpose also for SRF gasification in GazEla fixed bed reactor. This mechanism of control comprises of selective addition of steam into the stream of gasification agent (air) fed into specific process zones, by this it is possible to decrease the influence of temperature rise and observed process fluctuations.

\section{Conclusions}

Identified technological problems with SRF gasification in GazEla reactor are generic for this type of gas generators. Developed understanding enables now to conduct specific SRF gasification tests and process optimization research.

Literature research for fixed bed air gasification of SRF has proven to be very difficult due to very limited amount of information present in this specific field. Still it is thought that the only economically feasible option for development of small and medium scale SRF gasification system is based on air/steam mixture gasification in a fixed bed reactor connected to CHP unit generating heat and power. Such systems will provide separated, reliable source of independent heat and power for secluded small municipalities and companies generating wastes and by-products which otherwise would need to be landfilled.

\section{Acknowledgements}

Investigation presented in this paper is done according to the 23_2011_IP19_CoalGas contract between IChPW and KIC, the legal basis for implementation of the work is the approved research and development project 21.11.002 „Solid Recovered Fuel for renewable Combined Heat and Power production via gasification process". 


\section{References}

[1] Ladislav Bébar, Petr Stehlík, Leoš Havlen, Jaroslav Oral, Analysis of using gasification and incineration for thermal processing of wastes, Applied Thermal Engineering, Volume 25, Issue 7, May 2005, Pages 1045-1055, ISSN 1359-4311, http://dx.doi.org/10.1016/j.applthermaleng.2004.07.022.

[2] Stephen Burnley, Rhiannon Phillips, Terry Coleman, Terence Rampling, Energy implications of the thermal recovery of biodegradable municipal waste materials in the United Kingdom, Waste Management, Volume 31, Issues 9-10, September-October 2011, Pages 1949-1959, ISSN 0956053X, http://dx.doi.org/10.1016/j.wasman.2011.04.015.

[3] Mario Grosso, Astrid Motta, Lucia Rigamonti, Efficiency of energy recovery from waste incineration, in the light of the new Waste Framework Directive, Waste Management, Volume 30, Issue 7, July 2010, Pages 12381243, ISSN 0956-053X, http://dx.doi.org/10.1016/j.wasman.2010.02.036.

[4] S. Evangelisti, P. Lettieri, R. Clift, D. Borello, Distributed Generation By Energy From Waste Technology: A Life Cycle Perspective, Process Safety and Environmental Protection, Available online 1 April 2014, ISSN 09575820, http://dx.doi.org/10.1016/j.psep.2014.03.008.

[5] Umberto Arena, Fabrizio Di Gregorio, Gasification of a solid recovered fuel in a pilot scale fluidized bed reactor, Fuel, Volume 117, Part A, 30 January 2014, Pages 528-536, ISSN 0016-2361, http://dx.doi.org/10.1016/j.fuel.2013.09.044.

[6] http://www.lahtistreams.com/project_overview/.

[7] Janusz Kotowicz, Aleksander Sobolewski, Tomasz Iluk, Energetic analysis of a system integrated with biomass gasification, Energy, Volume 52, 1 April 2013, Pages 265-278, ISSN 0360-5442, http://dx.doi.org/10.1016/ j.energy.2013.02.048.

[8] Chart Chiemchaisri, Boonya Charnnok, Chettiyappan Visvanathan, Recovery of plastic wastes from dumpsite as refuse-derived fuel and its utilization in small gasification system, Bioresource Technology, Volume 101, Issue 5, March 2010, Pages 1522-1527, ISSN 0960-8524, http://dx.doi.org/10.1016/j.biortech.2009.08.061.

[9] Siyi Luo, Bo Xiao, Zhiquan Hu, Shiming Liu, Yanwen Guan, Lei Cai, Influence of particle size on pyrolysis and gasification performance of municipal solid waste in a fixed bed reactor, Bioresource Technology, Volume 101, Issue 16, August 2010, Pages 6517-6520, ISSN 0960-8524,

[10] In-Hee Hwang, Jun Kobayashi, Katsuya Kawamoto, Characterization of products obtained from pyrolysis and steam gasification of wood waste, RDF, and RPF, Waste Management, Volume 34, Issue 2, February 2014, Pages 402-410, ISSN 0956-053X.

[11] Ajay K. Dalai, Nishant Batta, I. Eswaramoorthi, Greg J. Schoenau, Gasification of refuse derived fuel in a fixed bed reactor for syngas production, Waste Management, Volume 29, Issue 1, January 2009, Pages 252-258, ISSN 0956-053X.

[12] Polish Patent application: P-383541 (2007). 